Running head: DOES SOCIAL-BEHAVIORAL ADJUSTMENT MEDIATE THE RELATION BETWEEN EXECUTIVE FUNCTION AND ACADEMIC READINESS?

PLEASE NOTE:

This is the author's version of the manuscript accepted for publication in [Journal of Applied Developmental Psychology]. Changes resulting from the publishing process, namely editing, corrections, final formatting for printed or online publication, and other modifications resulting from quality control procedures, may have been subsequently added.

The published version can be found in: Baptista, J., Osório, A., Martins, E. C., Verissimo, M., \& Martins, C. (2016). Does social-behavioral adjustment mediate the relation between executive function and academic readiness? Journal of Applied Developmental Psychology, 46, 22-30. doi:10.1016/j.appdev.2016.05.004 
Running head: DOES SOCIAL-BEHAVIORAL ADJUSTMENT MEDIATE THE RELATION BETWEEN EXECUTIVE FUNCTION AND ACADEMIC READINESS?

\section{Does social-behavioral adjustment mediate the relation between executive function and academic readiness?}

Joana Baptista $^{\mathrm{a}}$, Ana Osório ${ }^{\mathrm{b}}$, Eva Costa Martins ${ }^{\mathrm{c}}$, Manuela Verissimo ${ }^{\mathrm{d}}$ and Carla Martins ${ }^{\mathrm{e}}$

${ }^{a}$ Department of Applied Psychology, School of Psychology, University of Minho, Portugal; ${ }^{b}$ Cognitive and Social Neuroscience Lab; Post-Graduate Program on Developmental Disorders; Center for Biological and Health Sciences; Mackenzie Presbyterian University, São Paulo, Brazil; ${ }^{c}$ Maia University Institute-ISMAI \& Centre for Psychology at University of Porto, Maia, Portugal; ${ }^{\mathrm{d}}$ ISPA-University Institute, Lisbon, Portugal; ${ }^{\mathrm{e}}$ Human Cognition Laboratory, School of Psychology, University of Minho, Braga, Portugal

\section{Acknowledgements:}

Note: This research was supported by Grant COMPETE: FCOMP-01-0124-FEDER-015504 from FCT (Fundação para a Ciência e Tecnologia) and the European Regional Development Fund (FEDER) through the European program COMPETE (Operational Programme for Competitiveness Factors) under the National Strategic Reference Framework (QREN) attributed to the research project titled "Children's socio-emotional-cognitive school readiness: A longitudinal approach to its developmental course during preschool years" (PTDC/PSIEDD/114527/2009). The authors are very grateful to the students who helped with data collection. Special thanks go to the children, families and preschool teachers who participated in the study.

Corresponding author: Carla Martins, University of Minho, School of Psychology, Campus de Gualtar, 4710-057 Braga. E-mail: cmartins@psi.uminho.pt. 
Running head: DOES SOCIAL-BEHAVIORAL ADJUSTMENT MEDIATE THE RELATION BETWEEN EXECUTIVE FUNCTION AND ACADEMIC READINESS?

\section{Does social-behavioral adjustment mediate the relation between executive function and} academic readiness?

A large body of empirical literature emphasizes the importance of early academic readiness - namely the ability to perform basic academic tasks, such as counting and recognizing letters - for school achievement and adjustment during elementary years (Duncan et al., 2007; Hindman, Skibbe, Miller, \& Zimmerman, 2010; Lonigan, 2006; Romano, Babchishin, Pagani, \& Kohen, 2010). Indeed, in a meta-analytic study, involving 70 longitudinal studies, La Paro and Pianta (2000) concluded that academic and cognitive abilities in preschoolers predicted about $25 \%$ of the variance in academic and cognitive skills measured during the first and second grade. Thereby, identifying the contributors for early academic school readiness seems crucial for promoting future academic success.

Recently, research on school readiness has emphasized the importance of executive function for early math and literacy performance before school entry (Blair \& Razza, 2007; Espy et al., 2004; Fitzpatrick, McKinnon, Blair, \& Willoughby, 2014). However, less attention has been given to the processes by which executive capacities relate to academic school readiness. Interestingly, executive function has also been observed to predict early social and behavioral adjustment (Brophy, Taylor, \& Hughes, 2002; Diamantopoulou, Rydell, Thorell, \& Bohlin, 2007). Research has demonstrated that children who do not have appropriate executive function capacities are less able to control their impulsive behaviors and to regulate their emotions (Jahromi \& Stifter, 2008), which compromises their engagement with the classroom activities and thereby their readiness to school (Raver, 2002). In fact, substantial research has documented that young children exhibiting challenging behaviors and peer problems within the classroom are more likely to be at risk for early academic difficulties (Arnold, 1997; Ladd, Birch, \& Buhs, 
Running head: DOES SOCIAL-BEHAVIORAL ADJUSTMENT MEDIATE THE RELATION BETWEEN EXECUTIVE FUNCTION AND ACADEMIC READINESS?

1999; Ladd \& Burgess, 2001; McWayne, Fantuzzo, \& McDermott, 2004). Nevertheless, much of the research investigating academic readiness in preschoolers has been focused either on executive function or on social and behavioral development, and studies that bring these constructs together in one investigation are lacking. Furthermore, what is yet to be examined is whether social-behavioral adjustment is a potential mediator of the association between executive function and academic school readiness in preschoolers. The present study explored this issue, as it seems to hold promise for understanding processes underlying the contribution of executive function for early academic abilities.

\section{Executive function and academic school readiness}

Executive function is a collection of top-down processes that allow for conscious, goaldirected control of thoughts and actions (Diamond, 2013; Zelazo \& Carlson, 2012), including working memory, defined as the ability to maintain and manipulate information for short time periods; set-shifting or the ability to shift flexibly the focus of cognitive set and to adjust behavior accordingly; and inhibitory control, defined as the ability to inhibit an automatic, but non-

optimal, response (Blair \& Ursache, 2013). Recently, executive function has been observed to be associated with early academic abilities. Bull and colleagues (2011) found significant predictive relationships between executive functioning capabilities and math readiness in preschoolers, even after controlling for child IQ, age, and maternal education. Nayfeld, Fuccillo and Greenfield (2013) similarly concluded that greater executive function abilities were related to math skills, letter and word identification, and knowledge of story-and-print concepts, in 54-66-month old children. Moreover, Dilworth-Bart (2012) revealed that executive function mediated the association between home-environment quality and academic readiness in preschoolers, even after accounting for child verbal abilities, while other researchers (Clark, Pritchard, \& 
Running head: DOES SOCIAL-BEHAVIORAL ADJUSTMENT MEDIATE THE RELATION BETWEEN EXECUTIVE FUNCTION AND ACADEMIC READINESS?

Woodward, 2010) observed significant associations between executive function scores obtained at age 4 years and later academic achievements at 6 years. These findings suggest that executive function is central to academic readiness. Nevertheless, there has been little research integrating the study of executive function in preschoolers with the examination of other constructs also related to academic school readiness, with the exception of socioeconomic status and maternal education, children's verbal abilities and general intelligence (e.g., Dilworth-Bart, 2012; Espy et al., 2011; Fitzpatrick et al., 2014).

\section{Social-behavioral adjustment as a meditational mechanism}

Empirical findings suggest that children's social and behavioral development may be of particular interest for understanding individual differences in readiness to school. Indeed, in addition to executive function, mounting evidence has also documented the relationship between social-behavioral development and academic achievement and success during elementary years (e.g., Nigg, Quamma, Greenberg, \& Kusche, 1999; Riggs, Blair, \& Greenberg, 2003). Fewer studies, however, have examined this association during the preschool years. This is quite surprising given evidence of the constructive role of social competence and behavioral functioning, including internalizing and externalizing behaviors, in shaping adjustment. Indeed, both social and behavioral abilities are consider to be core developmental milestones of the preschool period (e.g., Bornstein, Hahn, \& Haynes, 2010). This developmental phase is a time when children are becoming more able in regulating their emotions and behavior, as well as more competent in solving social problems, in cooperating with others, and in making friends (Denham et al., 2003; Sroufe, 1997). Although still scarce, the existing research has demonstrated a link between those social and behavioral skills and early academic achievement and success (Ladd, Birch, \& Buhs, 1999; Ladd \& Burgess, 2001; McWayne, Fantuzzo, \& McDermott, 2004). For 
Running head: DOES SOCIAL-BEHAVIORAL ADJUSTMENT MEDIATE THE RELATION BETWEEN EXECUTIVE FUNCTION AND ACADEMIC READINESS?

example, Palermo and colleagues (2007) found that preschoolers' prosocial behaviors including the ability to manage conflicts and to cooperate with peers were positively correlated with academic readiness and with peer acceptance. In addition to the importance of social functioning for academic readiness, the authors have also reported that children's behavioral functioning, including their aggressive behaviors, was related to lower academic readiness and higher rates of peer rejection. Indeed, externalizing behavior problems-including symptoms of inattention, overactivity and oppositional behavior-have also been found to correlate with academic difficulties in literacy, language and mathematics in preschoolers (Arnold, 1997; Campbell, Shaw, \& Gilliom, 2000; Friedman-Weieneth et al., 2007; Lonigan et al., 1999). Moreover, research has documented the negative influence of internalizing behavior problems on pre-academic abilities (Bulotsky-Sheaver, Fantuzzo, \& McDemott, 2008). Indeed, in a recent study of Head Start children, Bulotsky-Shearer, Dominguez and Bell (2012) found that social withdrawal behaviors were associated with lower school readiness skills, in the areas of emergent literacy, language, and mathematics. In a longitudinal study, Bub, McCartney and Willet (2007) concluded that young children with both internalizing and externalizing behavior problems, exhibited lower cognitive abilities and achievement scores in first grade.

Interestingly, a growing number of studies have also revealed that social-behavioral dysfunction - including symptoms of inattention, impulsivity, physical aggression, and peer problems - is similarly related to impairments in executive abilities (Diamantopoulou, Rydell, Thorell, \& Bohlin, 2007). Executive functioning, revealed in the capacity to suppress an inappropriate response in a given situation and to flexibly choose alternative responses, enables children to better regulate their emotions and behaviors, which are core abilities needed to form and maintain positive social relationships (Brock, Rimm-Kaufman, Nathanson, \& Grimm, 2009), 
Running head: DOES SOCIAL-BEHAVIORAL ADJUSTMENT MEDIATE THE RELATION BETWEEN EXECUTIVE FUNCTION AND ACADEMIC READINESS?

and thus to foster academic success and adjustment. In fact, it has been established that greater executive abilities are associated with fewer internalizing and externalizing problems, and overall social competence in young children (Cole, Usher, \& Cargo, 1993; Eisenberg et al., 2000). For example, Jahromi and Stifter (2008) have documented that preschoolers with lower executive function capabilities showed poorer emotion regulation and were less able to control their impulsive behaviors. Similarly, Bierbman and colleagues (2008) found that executive abilitiesnamely working memory, inhibitory control and attention shifting or flexibility—predicted socioemotional competencies during the course of prekindergarten year. Brophy, Taylor and Hughes (2002) compared "hard-to-manage" 4-year-old children with typically developing peers. The authors found that, compared to controls, the 'hard-to-manage' group showed marked deficits in inhibitory control and planning, more errors on executive function tasks, and difficulties following rules. A study by Valiente and his colleagues (2008) is also noteworthy. These investigators examined cognitive and social contributors of academic achievement in a sample of 7-to-12-year-old students. They found that the quality of teacher-child relationship, social competence and classroom participation partially mediated the concurrent relation between children's regulatory abilities — assessed in terms of effortful control or the ability to inhibited a dominant response, to plan, and detect errors-, and changes in grade point averages from the beginning to the end of the school year. In another study from the same research team, the authors have found that social functioning - i.e., a composite variable consisting of the social competence and the behavior functioning scores - fully mediated the relation between effortful control at 73 months and academic achievement at 12 years (Valiente et al., 2011). Oberle and Reichl (2013), in a study with 4th and 5th grade early adolescents, also added to the literature, by showing that both executive function, assessed in terms of inhibitory control, and peer acceptance 
Running head: DOES SOCIAL-BEHAVIORAL ADJUSTMENT MEDIATE THE RELATION BETWEEN EXECUTIVE FUNCTION AND ACADEMIC READINESS?

were significantly and positively related to math achievement. Furthermore, the authors also found that peer acceptance was significantly linked to inhibitory control, and acted as a mediator in the relation between inhibitory control and math achievement. These findings suggest that both cognitive and social and behavioral functioning are relevant for academic success, and that social and behavioral competencies might mediate the link between executive function and academic readiness.

Notwithstanding the aforementioned research, very few reports have examined the relations between both executive function and social-behavioral adjustment and academic achievement before school entry, and thus the question remains whether social-behavioral adjustment accounts for the relation between executive function and academic school readiness. It is possible that impairments in executive function, revealed in inadequate attentional and behavioral regulatory skills, may affect preschoolers' social and behavioral adaptation in the classroom, and thus the degree to which they benefit from their structured academic experiences with teachers and peers (Denham, 2006; Raver, 2002). Furthermore, there has been little examination of those relationships in samples of middle-class children, as studies have been mainly focused on disadvantaged Head Start preschoolers.

\section{The present study}

In light of the above, the present study seeks to contribute to the literature by examining the relationships between executive function, social-behavioral adjustment, and academic school readiness in a sample of middle-class preschoolers. In this article, social-behavioral adjustment was operationalized in terms of social competence, and internalizing and externalizing behaviors, as all of these have been found to be core developmental abilities of the preschool period (Bornstein, Hahn, \& Haynes, 2010). Furthermore, this study also aims to extend what is known 
Running head: DOES SOCIAL-BEHAVIORAL ADJUSTMENT MEDIATE THE RELATION BETWEEN EXECUTIVE FUNCTION AND ACADEMIC READINESS?

about executive function and pre-academic abilities by examining whether such relationship is mediated by social and behavioral adaptation. It is hypothesized that children performing better on executive function tasks — namely inhibitory control, working memory and set-shiftingwould show higher social competency and behavior adaptation, which would predict early academic abilities.

\section{Method}

\section{$\underline{\text { Participants }}$}

$\underline{\text { Eighteen child-care centers in a metropolitan area of northern Portugal were initially }}$ contacted within a longitudinal study on the developmental predictors of school readiness. The purposes of the study as well as detailed procedure were presented to 200 families. Seventy-seven families agree to participate. For the present investigation, data was available for 69 children (33 girls, 47.8\%) who attended 14 preschools. . Children's age ranged from 63 to 76 months $(M=$ 69.26, $S D=3.15)$. All were white and the majority came from two-parent families $(n=58$, $84.1 \%)$ with two or more children $(n=49,71 \%)$. One $(n=1.4 \%)$ mother had not completed high school, $16 \%(n=11)$ of the mothers had obtained a high school diploma and the remaining $(n=$ $57,82.6 \%$ ) had graduated from college. Participants also included the preschool teachers that completed reports regarding children's variables. In all preschools, teachers used the same curriculum, provided by the Portuguese Ministry of Education. All teachers had at least a bachelor's degree.

\section{Procedure}

Data were collected in the last semester of the preschool year, four months before entry in primary school. Parents were first explained the purposes of the study as well as the detailed procedure, and gave their written informed consent for their children's participation. Children 
Running head: DOES SOCIAL-BEHAVIORAL ADJUSTMENT MEDIATE THE RELATION BETWEEN EXECUTIVE FUNCTION AND ACADEMIC READINESS?

were tested individually over two 45-min sessions at the preschool in which they were enrolled or in a university laboratory setting. Two trained experimenters administered the tasks, and intervals between sessions were never longer than two weeks. Sessions were videotaped and the children received a small gift for their participation. Their preschool teachers were asked to fill in a questionnaire on children's social and behavioral competence.

\section{Measures}

Academic school readiness. The Lollipop Test (Chew \& Morris, 1984) is an individually administered and well-validated diagnostic screening test of academic readiness in preschoolaged children. It includes 52 items, divided in four subtests concerning (i) knowledge about colors and shapes and ability to copy shapes (14 items), (ii) description of images and spatial recognition (10 items), (iii) knowledge about numbers and counting (14 items), and (iii) knowledge about letters and writing (14 items). The Lollipop Test was developed and validated in the USA, with good levels of concurrent validity with the Metropolitan Readiness Tests (MRT), and with teachers' evaluations. A total final score was calculated based on the sum of the items. The minimum and maximum scores children could attain were 0 and 69 , respectively.

Executive function. Executive functioning was measured using three tasks designed to assess inhibitory control, working memory, and cognitive flexibility. All of these tasks have been extensively used to assess preschoolers' executive function (e.g., Carlson, 2005; Wanless et al., 2011). Inhibitory control was assessed using the Head-Toes-Knees-Shoulders task (HTKS; Ponitz, McClelland, Matthews, \& Morrison, 2009), a structured observation requiring children to perform the opposite of a dominant response to different oral commands. The HTKS task includes 20 test trials. Children are initially instructed to respond in an unusual manner to a two rules (head/toes) command (item 1 - 5; e.g., if the experimenter says "Touch your head", the 
Running head: DOES SOCIAL-BEHAVIORAL ADJUSTMENT MEDIATE THE RELATION BETWEEN EXECUTIVE FUNCTION AND ACADEMIC READINESS?

correct answer would be for the child to touch his or her toes), following two novel

(knees/shoulders) commands (items 6 - 10; e.g., if the experimenter says "Touch your knees", the correct answer would be for the child to touch his or her shoulders). Then, task complexity increases by asking children to respond simultaneously to one of four commands (head/toes/knees/shoulders) (items $11-20$ ). Each of the 20 items was scored with 0 for an incorrect response, 1 for a self-correct response, or with 2 for a correct response. The total score ranges from 0 to 40, with higher scores being indicative of higher levels of inhibitory control.

Working memory was assessed using the Backward Digit Span task (BDS; Davis \& Pratt, 1995). In the BDS, children are invited to verbally repeat in reverse order sequences of single-digit numbers. Following a two-digit practice trial, children are given two trials for each test sequence, until they fail two consecutive trials of a given length. The highest level of success is recorded. In order to assess set-shifting, the Executive Function Scale for Early Childhood (Carlson \& Schaefer, 2012) was used, which consists of an adaptation of the Dimensional Change Card Sort task (DCCS; Frye, Zelazo, \& Palfai, 1995). In these task, children are required to sort a series of bivalent cards into boxes with target cards on them. The sorting cards (e.g., red star and blue car) match each target card (e.g., a blue star and a red car) on exactly one dimension. The DCCS offers seven distinct phases of complexity. For children aged 5 years, task begins in the fifth phase, in which participants are asked to sort the cards based on two dimensions, specifically by color or shape, according to the instructions of the experimenter; thereby requiring that the cards be sorted into opposite boxes (10 items). In the sixth phase, children are required to sort according to another dimension (border vs. non-border); if a black border is presented in the card, children should sort according to color, but if there is not, children should sort according to shape (10 items). Finally, in the last phase of the task, children are instructed to reverse the rule, sorting 
Running head: DOES SOCIAL-BEHAVIORAL ADJUSTMENT MEDIATE THE RELATION BETWEEN EXECUTIVE FUNCTION AND ACADEMIC READINESS?

by color if the card has no black border, or sorting by shape if the card has a black border (10 items). Children were considered to have passed each phase when they correctly sorted four or more cards for each condition of that particular phase (e.g., in the fifth phase, four or more corrected answer when asked to sort by color and four or more corrected answers when asked to sort by shape). When children failed the fifth phase, the experimenter had to administer the lower difficulty DCCS sorting tests in a predetermined order, in which children were asked to sort the cards base on only one dimension (e.g., by color); if children failed the sixth or seventh phase, the task ended.

Inhibitory control, working memory and set-shifting scores were standardized and submitted to a principal component analysis. This analysis yielded a one-component solution, eigenvalue $=1.68$ (eigenvalue greater than 1; Fabrigar, Wegener, McCallum, \& Strahan, 1999; Kaiser, 1960), representing 58\% of the total variance. Component loadings were .63 for inhibitory control, .79 for working memory, and .81 for set-shifting. These three executive function tasks were found to be mildly intercorrelated (inhibitory control and working memory, $r$ $=.25, p=.045$; inhibitory control and set-shifting, $r=.29, p=.016$; and working memory and set-shifting, $r=.47, p<.001)$. This result is in line with previous findings, showing that a single factor model best explained the performance on executive function tasks among preschool children, and that a unitary perspective of executive abilities is more appropriate during this developmental period (Wieber, Nelson, Clark, \& Espy, 2011). Thereby, in the present study, a composite of executive function was calculated, consisting on the mean of the standardized scores of the inhibitory control, working memory, and set-shifting tasks. This composite was used in further analysis. 
Running head: DOES SOCIAL-BEHAVIORAL ADJUSTMENT MEDIATE THE RELATION BETWEEN EXECUTIVE FUNCTION AND ACADEMIC READINESS?

Social-behavioral adjustment. Preschool teachers filled in the Portuguese short version of the Social Competence and Behavior Evaluation scale (SCBE-30; LaFreniere \& Dumas, 1996; Portuguese version by Santos \& Veríssimo, 2008) and the Portuguese version of the Caregiver Teacher Report Form for children 1.5-5 years of age (CTRF; Achenbach, 2000; Gonçalves, Dias, \& Machado, 2007), in order to assess both children's prosocial and behavior adaptation. The SCBE-30 consists of 30 items, rated from 1 (never occurs) to 6 (always occurs). There is also an option available for behaviors teachers feel they cannot evaluate. The items are organized in three subscales, namely the social competence subscale, the aggression subscale and the anxiety subscale, each consisting of 10 items. In the present inquiry, only the social competence subscale was used, tapping a broad range of behaviors that indicate generally prosocial pattern of social adaptation (e.g., Item 13, negotiates solutions to conflicts; Item 17, cooperates with other children). Higher scores reflect greater social adjustment. The CTRF consists of 100 problem items that describe behavioral/emotional difficulties, and which are rated by teachers on a 3point-scale $(0=$ not true, $1=$ sometimes/somewhat true or $2=$ very/frequently true. The CTRF comprises a scale of internalizing behavior problems - assessing anxiety/depressive symptoms, somatic complaints, and withdrawn behavior-, a scale of externalizing behavior problemsassessing attention and oppositional problems-, and a total problem scale. In the present inquiry, both the internalizing and externalizing scales were used.

Based on an organizational perspective of development (Sroufe, Egeland, \& Kreutzer, 1990), from which adjustment is defined with respect to the quality of the integration among salient domains of function of a particular developmental period, in the present study the social competence, and the internalizing and externalizing behavior scores (initially reversed, so that higher scores reflected greater behavioral competence) were standardized and submitted to a 
Running head: DOES SOCIAL-BEHAVIORAL ADJUSTMENT MEDIATE THE RELATION BETWEEN EXECUTIVE FUNCTION AND ACADEMIC READINESS?

principal component analysis. Consistent with others (Valiente et al., 2011), this analysis yielded a one-component solution, eigenvalue $=1.72$, representing $57.2 \%$ of variance. Composite loadings were found to be all higher than .50 (.72 for social competence, .79 for internalizing behaviors, and .75 for externalizing behaviors). Social competence, and internalizing and externalizing behavior scores proved to be all significant related to each other: social competence and internalizing behaviors, $r=.36, p=.002$; social competence and externalizing behaviors, $r=$ $.31, p=.011$; and internalizing and externalizing behaviors, $r=.40, p=.001$. In the present inquiry, a composite of social-behavior adjustment was calculated, consisting on the mean of the standardized scores of the social competence subscale of the SCBE-30 and of the internalizing and externalizing scales of the CTRF, with higher scores reflecting better global social-behavioral adjustment. This composite was used in further analysis.

Verbal ability. Child verbal ability was assessed using the Peabody Picture Vocabulary Test, revised edition (PPVT-R; Dunn \& Dunn, 1981). Children were orally presented with words, and asked to choose from a set of four pictures, which one corresponded to the word previously heard. The coding consists on subtracting the total number of errors made by children during the test from the highest item children got to. Raw scores were used as the final measure of verbal ability as Portuguese norms for this instrument are not yet available.

\section{Analytic strategy}

Data analysis proceeded in several steps. First, simple bivariate relations were examined between academic school readiness and control variables, namely age at assessment, verbal ability, as well as maternal education. Sex differences were also analyzed. Then, correlations between executive function (predictor), social-behavioral adjustment (mediator) and academic school readiness (outcome variable) were also examined. Finally, we tested whether social- 
Running head: DOES SOCIAL-BEHAVIORAL ADJUSTMENT MEDIATE THE RELATION BETWEEN EXECUTIVE FUNCTION AND ACADEMIC READINESS?

behavioral adjustment mediated the effects of executive function on academic school readiness, based on a causal-steps approach (Baron \& Kenny, 1986).

\section{Results}

\section{Descriptive and control variables: Age, sex, verbal ability and maternal education}

Descriptive statistics and bivariate correlations between study variables can be found in Table 1 and Table 2, respectively. Children who demonstrated greater academic school readiness had mothers with higher levels of education, and showed greater verbal ability. No significant associations were found between academic school readiness and child age. Similarly, there were no sex differences on academic school readiness, $t(67)=-.99, p=.32$.

\section{Predictor and mediator: Executive function and social-behavioral adjustment}

Children who exhibited better executive function and socio-behavioral adjustment according to teachers' reports showed greater academic school readiness. Positive correlations were observed between executive function and child verbal ability, and social-behavioral adjustment. There were no sex differences on executive function, $t(67)=.31, p=.76$, and on socio-behavioral adjustment, $t(67)=-.25, p=.88$.

:::Insert Table 1 around here:::

:::Insert Table 2 around here:::

\section{Mediation model}

Given the significant association between executive function and social-behavioral adjustment, and between both and academic school readiness, the causal-steps method (Baron \& Kenny, 1986) was used to examine whether social-behavioral adjustment mediated the link between executive function and academic school readiness. The causal-steps approach tests (i) whether the effect of the predictor (executive function) on the dependent variable (academic 
Running head: DOES SOCIAL-BEHAVIORAL ADJUSTMENT MEDIATE THE RELATION BETWEEN EXECUTIVE FUNCTION AND ACADEMIC READINESS?

school readiness) is significant (path c); (ii) whether the effect of the predictor on the mediator (social-behavioral adjustment) is significant (path $\alpha$ ); (iii) whether the effect of the mediator on the dependent variable is significant (path $\beta$ ); and (iv) whether the effect of the predictor on the dependent variable, while controlling for the mediator, is smaller (path $c^{\prime}$ ) than the total effect of the predictor on the dependent variable (path $c$ ) (Figure 1).

Four linear regressions were computed in order to determine if the conditions required for a mediation to occur were met. The first condition, which specifies that a linear relationship must exist between executive function and academic school readiness, was satisfied. Given the significant associations with academic school readiness, child verbal ability and maternal education were included in the first step of the analysis as control variables. They both proved to be significant predictors of academic readiness, explaining $24 \%$ of the variance in academic school readiness. Executive function was then entered in the second block of the model, and proved to be a significant predictor of academic school readiness, Path $c, \beta=.27, t=2.12, p=$ .038 , explaining additional $6 \%$ of the variance (Figure 1A and Table 3, see Block 1 and 2 of the regression model). The second and third conditions were also satisfied, demonstrating a relationship between the predictor (executive function) and the mediator (social-behavioral adjustment), Path $\alpha ; \beta=.42, t=3.72, p<.001$, explaining $16 \%$ of the variance; and between social-behavioral adjustment and the dependent variable (academic school readiness), Path $\beta ; \beta=$ $.25, t=2.31, p=.024$, even after controlling for verbal ability and maternal education, and for executive function, increasing the amount of variance explained to $33 \%$ (Figure 1B). Finally, the relationship between the predictor and the dependent variable was reexamined while statistically controlling for the mediator variable. The effect of executive function on academic school readiness became statistically non-significant, followed by a reduction in $\beta$ of $37 \%$, when 
Running head: DOES SOCIAL-BEHAVIORAL ADJUSTMENT MEDIATE THE RELATION BETWEEN EXECUTIVE FUNCTION AND ACADEMIC READINESS?

controlled for the effect of social-behavioral adjustment, Path $c^{\prime} ; \beta=.17, t=1.31, p=.20$ (Table 3, see Block 3 of the regression analysis). Thus, as Figure 1B illustrates, social-behavioral adjustment was identified as a mediator of the effect of executive function on academic school readiness.

In order to identify the confidence intervals of indirect effects, Preacher and Hayes' (2004) bootstrapping methodology on 5.000 bootstrap resamples was carried out. The bootstrapped unstandardized indirect effect was .77 , and the $95 \%$ confidence interval ranged from .25 to 1.72 . Because zero was not in the confidence interval, we conclude that the indirect effect is significantly different from zero at $p<.05$ (two-tailed). Such results support socialbehavioral adjustment as a mediator of the link between executive function and academic school readiness. As devised in Preacher and Kelley (2011), the kappa-squared was then calculated, showing that the significant indirect effect of executive function on academic school readiness through social-behavioral adjustment represents a medium effect, $k^{2}=11.77,95 \%$ CI [.04-.27]. :::Insert Table 3 around here::: :::Insert Figure 1 around here:::

\section{Discussion}

In a survey of more than 3500 kindergarten teachers, conducted by Rimm-Kaufman and colleagues (2000) in the United States, teachers reported that about one-third of the students in their classrooms had problems making the transition to school and about one-fifth had serious adjustment difficulties including lack of academic competencies. Given that a growing body of research suggests that such pre-academic skills, including literacy and math abilities, are strong predictors of later school achievement and success (Duncan et al., 2007; La Paro \& Pianta, 2000), examining the contributors of such skills is crucial. On this matter, although theory and empirical 
Running head: DOES SOCIAL-BEHAVIORAL ADJUSTMENT MEDIATE THE RELATION BETWEEN EXECUTIVE FUNCTION AND ACADEMIC READINESS?

findings (e.g., Blair, 2002) have emphasized the importance of both executive function and social-behavioral adjustment for academic readiness, few studies have sought to bridge the two, with notable exceptions mainly focused on school-aged children and adolescents (Oberle \& Reichl, 2013; Valiente et al., 2008). Thereby, the present study aimed to extend current understanding about the mechanisms by which executive function relate to academic school readiness in a sample of middle-class preschoolers, by examining whether social and behavioral adaptation mediated such relationship before school entry.

Results indicate that social-behavioral adjustment acted as a mediator in the link between executive function and indicators of academic abilities, even after controlling for maternal education and child verbal competence. Additionally, our findings provided support for the associations between executive function and social-behavioral adjustment, and between both and academic school readiness, in a sample of children from low-risk settings, adding to the literature mainly focused on low-income Head Start preschoolers. This data is consistent with crosssectional and longitudinal findings (Oberle \& Reichl, 2013; Valiente et al., 2011; Valiente et al., 2008), showing that (at least part of) the reason why students with higher executive function abilities perform better on academic tasks is because they are more social competent and behave more appropriately in the school context. Moreover, this significant mediation also expands such previous literature, by showing that executive function contributes to early academic achievement by influencing children's social and behavioral adjustment, even before school entry. Indeed, as evidenced by an accumulating body of research, preschoolers who have poorer executive function are more prone to exhibit behavior problems, including lack of concentration, impulsivity and physical aggression, as well as difficulties regulating their emotions in the classroom, thus suffering from peer rejection (Brophy, Taylor, \& Hughes; 2002; Jahromi \& 
Running head: DOES SOCIAL-BEHAVIORAL ADJUSTMENT MEDIATE THE RELATION BETWEEN EXECUTIVE FUNCTION AND ACADEMIC READINESS?

Stifter, 2008). Such findings from previous studies, alongside with ours, are particularly noteworthy, given the fact that many classroom practices, especially in preschool, rely on opportunities for social interactions in small-group settings. Thereby, and as in preschool learning is primarily a socially mediated experience (Bulotsky-Shearer, Dominguez, \& Bell, 2012), it is expected that more inadequate social-emotional-behavioral trajectories will consequently interfere with children's opportunities to experience positive interactions with teachers and peers in the classroom activities that support the development of early academic competencies. This last assumption was confirmed by vast research on the topic. Indeed, children with more social and behavioral problems have been found to participate less in classroom activities, to receive less assistance and positive feedback from their teachers, to experience less positive relationships with peers, to miss out on learning opportunities, and to like school to a lower extent, being, consequently, at risk for concurrent and later academic difficulties (Blair, 2002; Denham, 2006; Hamre \& Pianta, 2001; Raver \& Knitzer, 2002).

In addition, it is important to note that maternal education proved also to be a significant predictor of academic school readiness, accounting for a large proportion of variance, even more than executive function, which, although being a significant predictor of school readiness as observed here and elsewhere (e.g., Nayfeld, Fuccillo, \& Greenfield, 2013), contributed to a less extent to the variation in academic readiness scores. It is possible that difficulties in executive function capacities are more problematic for learning and achievement in the following years of schooling, which are more challenging for students. For instances, in elementary school, children are required to stay quiet for longer periods of time, they receive longer sentences of instructions from their teachers, and they are asked to solve more complex academic tasks requiring alternation between different aspects of problems. 
Running head: DOES SOCIAL-BEHAVIORAL ADJUSTMENT MEDIATE THE RELATION BETWEEN EXECUTIVE FUNCTION AND ACADEMIC READINESS?

Also of note is the fact that the significant association found in this study between maternal education and school readiness points to the relevance of environmental factors to the acquisition of pre-academic abilities, and is consistent with previous findings, showing that higher levels of maternal education are linked to better academic achievement in young children (Dilworth-Bart, 2012; Geoffroy et al., 2010). A possible explanation is that more educated mothers are more likely to select high-quality, enriched, child-care centers, and are more able to engage in high quality interactions with their children, which, in turn, may boost academic readiness. These findings suggest the need for research to further explore the contribution of family factors, and especially to disaggregate maternal education in other features of home quality, in order to analyze how much of individual differences in academic readiness is explained by both family distal and proximal processes. The mechanisms by which the quality of family environment affects academic school readiness also needs to be further investigated.

Moreover, verbal ability was also found to predict academic readiness, becoming this relation non-significant after the inclusion of executive function in the model. This result is also consistent with the literature, suggesting that verbal ability and executive function are related entities (Blair, 2003; Müller, Zelazo, \& Imsirek, 2005). Studies have, indeed, revealed that verbal ability acts as a prerequisite of executive function, and is linked to changes in the course of the development of executive competencies during the early years of life (Fuhs \& Day, 2011).

\section{Implications for policy and practice}

The results of our study have important implications for preschool curricula and educational policy. Given our results that lower levels of executive function and social and behavioral adaptation are associated with difficulties in pre-academic competencies, it is therefore crucial to promote the early detection of difficulties in both domains, in order to foster 
Running head: DOES SOCIAL-BEHAVIORAL ADJUSTMENT MEDIATE THE RELATION BETWEEN EXECUTIVE FUNCTION AND ACADEMIC READINESS?

early academic achievement. For such purpose, preschool educators and policy makers should be informed of the importance of such factors for predicting positive academic outcomes.

Simultaneously, efforts should continue to be made, in order to provide educators with assessment tools easy-to-implement, focused on executive function, as well as on social and behavioral adjustment, which in turn would allow them to carry out target, and more individualized, interventions - both remedial and universal — for young children, before school entry.

Interestingly, it is noteworthy that efforts to promote school readiness have been mainly focused on curriculum modifications, in order to stimulate the acquisition of key emergent literacy and numeracy skills, such as counting and recognizing letters (Landry, Swank, Smith, Assel, Gunnewig, 2006; Starkey, Klein, \& Wakeley, 2004). Despite the undoubted importance of such work, our findings also underline the need to implement early intervention programs aimed at the development of executive function. As executive abilities are related to gains in social and behavioral functioning during the preschool years, and both are linked to academic success, a greater emphasis on such cognitive processes, before school entry, may promote preschoolers' interpersonal functioning and their engagement with the classroom activities. Such social and emotional improvements may, in turn, affect positively children's early math and literacy performance (Durlak, Weissberg, Dymnicki, Taylor, \& Schellinger, 2011).

Many activities aimed at improving preschoolers' executive function capacities could be, in fact, implemented in the classroom. Indeed, recent and innovative training programs have proven effective in enhancing executive function (Diamond, Barnett, Thomas, \& Munro, 2007; Röthlisberger, Neuenschwander, Cimeli, Michel, \& Roebers, 2011). For instance, in a randomized-controlled trial curriculum intervention, carried out with 354 4-year-old children, 
Running head: DOES SOCIAL-BEHAVIORAL ADJUSTMENT MEDIATE THE RELATION BETWEEN EXECUTIVE FUNCTION AND ACADEMIC READINESS?

Bierman and colleagues (2008) confirmed the central role of executive function in fostering academic readiness. Specifically, the authors observed a significant effect for the Head Start REDI [Research-Based, Developmentally Informed] intervention in executive competencies, which, in turn, predicted gains in school readiness. Moreover, research should continue efforts to create interventions to improve parents' competences to stimulate their children's executive abilities. By doing so, parents may be also enhancing the development of their children's optimal social and behavioral functioning, and setting the stage for subsequent academic success.

Following our data, showing that social-behavioral adjustment is linked to academic school readiness, and, more specifically, is a mediator in the relation between executive function and early academic abilities, additional, and direct, social and behavioral training within the classroom and home environment may be also a successful mechanism for improving academic school readiness. Thereby, strengthening preschoolers' capacities to manage their behavior and to act in a more socially appropriate manner, alongside with their executive function capacities, may serve an important protective function for academic achievement and success.

\section{Limitations and future directions}

Our study expands current knowledge on the relationships between executive function, social-behavioral adjustment and academic school readiness by advancing a mediation model whereby the effect of executive function on academic school readiness occurs via improved social-behavioral adjustment. Nevertheless, there are several limitations to this report that should be addressed in future research. Even though the sample size was reasonable, the recruitment success rate of the present study was of only $35 \%$, which might have had impact on the representativeness of our final sample. Moreover, being a cross-sectional study, information regarding the main study variables was available for a single point in time. Thereby, the 
Running head: DOES SOCIAL-BEHAVIORAL ADJUSTMENT MEDIATE THE RELATION BETWEEN EXECUTIVE FUNCTION AND ACADEMIC READINESS?

correlation design of our study limits the interpretation of the results, and do not allow for firm conclusions about directionality. Generalization of the results must be made carefully, and future work should be longitudinal in design, with assessments of executive function and socialbehavioral adjustment at the beginning of the preschool period and at subsequent moments. Furthermore, data concerning preschoolers' social-behavioral adjustment was based exclusively on teachers' perceptions. Incorporating parents' perspective and even observational measures could provide a more comprehensive view of children's social and behavioral adaptation.

In addition, the effects of other possible contributors to pre-academic abilities remain unknown. On this matter, it is important to note that, in the present study, the significant indirect effect of executive function on academic readiness, via social-behavioral adjustment, proved to be of medium effect. This result suggests that other factors may be also contributing directly to academic school readiness, or even mediating the relation between executive function (and even social-behavioral adjustment) and academic readiness. The quality of teacher-student relationship may be of particular relevance, as previous studies have found that a more positive relationship between teacher and student, during the preschool period, is linked to academic achievement in those and in the following years (Hamre \& Pianta, 2001; Palermo et al., 2007). Additionally, and as already mentioned in the present inquiry, other authors have observed that the quality of teacher-student relationship acted as a significant mediator in the relation between effortful control and academic success (Valiente et al., 2008). In line with this data, future studies should incorporate the putative contribution of the quality of preschool social environment, when exploring the mechanisms underlying the links between executive function, social-behavioral adjustment, and academic readiness. 
Running head: DOES SOCIAL-BEHAVIORAL ADJUSTMENT MEDIATE THE RELATION BETWEEN EXECUTIVE FUNCTION AND ACADEMIC READINESS?

Moreover, and notwithstanding the importance of school factors, it is even possible that individual differences in academic readiness - but also in executive function and social and behavioral adjustment - may partially result from differences in quality of parenting over time. On this matter, various studies indicate that children who experience more warm and sensitive parenting during toddlerhood latter display better executive functioning abilities and socialbehavioral adaptation (e.g., Bernier, Carlson, \& Whipple, 2010; Roskam, Stievenart, Meunier, \& Noël, 2014; Rubin, Burgess, Dwyer, \& Hastings, 2003). Authors have also reported that parental engagement and responsiveness contribute to academic school readiness (Connell \& Prinz, 2002; Miedel \& Reynolds, 1999). Considering such observations, one can expect that greater quality of parental care may significantly influence the relations between executive function and social and behavioral development and readiness outcomes. Future work adopting a longitudinal design may clarify whether such associations are extended over the first years of life until school transition. Finally, in future follow-up studies, researchers can extend understanding of the influence of executive function and social-behavioral adjustment on children's academic readiness, by investigating whether the present results may be generalizable to children growing up in socioeconomic high-risk settings, as this study was focused on middle-income children, from well-educated homes. 
Running head: DOES SOCIAL-BEHAVIORAL ADJUSTMENT MEDIATE THE RELATION BETWEEN EXECUTIVE FUNCTION AND ACADEMIC READINESS?

\section{References}

Achenbach, T.M., \& Rescorla, L.A. (2000). Manual for the ASEBA preschool-age forms \& profiles. Burlington, VT: University of Vermont, Research Center for Children, Youth, \& Families.

Arnold, D. H. (1997). Co-occurrence of externalizing behavior problems and emergent academic difficulties in young high-risk boys: A preliminary evaluation of patterns and mechanisms. Journal of Applied Developmental Psychology, 18(3), 317-330. doi:10.1016/S0193-3973(97)80003-2.

Baron, R. M., \& Kenny, D. A. (1986). The moderator-mediator variable distinction in social psychological research: Conceptual, strategic, and statistical considerations. Journal of Personality and Social Psychology, 51(6), 1173-1182. doi: 10.1037/0022-3514.51.6.1173.

Bernier, A., Carlson, S., \& Whipple, N. (2010). From external regulation to self-regulation: Early parenting precursors of young children's executive functioning. Child Development, 81(1), 326-339. doi: 10.1111/j.1467-8624.2009.01397.x.

Bierbman, K. L., Nix, R. L., Greenberg, M. T., Blair, C., Domitrovich, C. E. (2008). Executive functions and school readiness intervention: Impact, moderation, and mediation in the Head Start REDI program. Developmental Psychopathology, 20(3), 821-843. doi: $10.1017 / \mathrm{S} 0954579408000394$.

Blair, C. (2002). School readiness: Integrating cognition and emotion in a neurobiological conceptualization of children's functioning at school entry. American Psychologist, 57(2), 111-127. doi: 110.1037//0003-066X.57.2.111. 
Running head: DOES SOCIAL-BEHAVIORAL ADJUSTMENT MEDIATE THE RELATION BETWEEN EXECUTIVE FUNCTION AND ACADEMIC READINESS?

Blair, C. (2003). Behavioral inhibition and behavioral activation in young children: Relations with self-regulation and adaptation to preschool in children attending Head Start.

Developmental Psychobiology, 42(3), 301-311. doi: 10.1002/dev.10103.

Blair, C., \& Razza, R. P. (2007). Relating effortful control, executive function, and false belief understanding to emerging math and literacy ability in kindergarten. Child Development, 78(2), 647-663. doi: 10.1111/j.1467-8624.2007.01019.

Blair, C., \& Ursache, A. (2013). A bidirectional modelo of executive functions and selfregulation. In K. Vohs \& R. Baumeister (Eds.), Handbook of self-regulation: Research, Theory and Applications. New York: The Guildford Press.

Bornstein, M. H., Hahn, C. S., \& Haynes, O. M. (2010). Social competence, externalizing, and internalizing behavioral adjustment from early childhood through early adolescence: Developmental cascades. Developmental Psychopathology, 22(4), 717-735. doi: 10.1017/S0954579410000416.

Brock, L. L., Rimm-Kaufman, S. E., Nathanson, L., \& Grimm, K. J. (2009). The contribution of 'hot' and 'cool' executive function to children's academic achievement and classroom behavior. Early Childhood Research Quarterly, 24, 337-349. doi: 10.1016/j.ecresq.2009.06.001.

Brophy, M., Taylor, E., Hughes, C. (2002). To go or not to go: Inhibitory control in "hard to manage" children. Infant and Child Development, 11, 125-140. doi: 10.1002/icd.301.

Bub, K. L., McCartney, K., \& Willett, J. B. (2007). Behavior problem trajectories and first-grade cognitive ability and achievement skills: A latent growth curve analysis. Journal of Educational Psychology, 99, 653-670. doi:10.1037/0022-0663.99.3.653.

Bull, R., Espy, K. A., Wiebe, S. A., Sheffield, T. D., \& Nelson, J. M. (2011). Using confirmatory 
Running head: DOES SOCIAL-BEHAVIORAL ADJUSTMENT MEDIATE THE RELATION BETWEEN EXECUTIVE FUNCTION AND ACADEMIC READINESS?

factor analysis to understand executive control in preschool children: Sources of variation in emergent mathematic achievement. Developmental Science, 14(4), 679-692. doi: 10.1111/j.1467-7687.2010.01012.x.

Bulotsky-Shearer, R., Dominguez, X., \& Bell, E. (2012). Preschool classroom behavioral context and school readiness outcomes for low-income children: A multilevel examination of child- and classroom-level influences. Journal of Educational Psychology, 104(2), 421438. doi: $10.1037 / \mathrm{a} 0026301$.

Bulotsky-Shearer, R., Fantuzzo, J. W., \& McDermott, P. A. (2008). An investigation of classroom situational dimensions of emotional and behavioral adjustment and cognitive and social outcomes for Head Start children. Developmental Psychology, 44, 139-154. doi:10.1037/0012-1649.44.1.139. doi: 10.1037/0012-1649.44.1.139.

Campbell, S., Shaw, D., \& Gilliom, M. (2000). Early externalizing behavior problems: Toddlers and preschoolers at risk for later maladjustment. Developmental Psychopathology, 12(3), 467-488. doi: 10.1017/S0954579400003114.

Carlson, S. (2005). Developmentally sensitive measures of executive function in preschool children. Developmental Neuropsychology, 28(2), 595-616. doi: $10.1207 / \mathrm{s} 15326942 \mathrm{dn} 2802 \_3$.

Carlson, S. M., \& Schaefer, C. (2012). Executive Function Scale for Early Childhood: Test Manual. University of Minnesota. Minneapolis, MN.

Chew, A. L. \& Morris, J. D. (1984). Validation of the Lollipop Test: A diagnostic screening test of school readiness. Educational and Psychological Measurement, 44, 987-991.

Clark, C. A., Pritchard, V. E., \& Woodward, L. J. (2010). Preschool executive functioning abilities predict early mathematics achievement. Developmental Psychology, 46(5), 1176- 
Running head: DOES SOCIAL-BEHAVIORAL ADJUSTMENT MEDIATE THE RELATION BETWEEN EXECUTIVE FUNCTION AND ACADEMIC READINESS?

1191. doi: $10.1037 / \mathrm{a} 0019672$.

Cole, P. M., Usher, B. A., \& Cargo, A. P. (1993). Cognitive risk and its association with risk for disruptive behavior disorder in preschoolers. Journal of Clinical Child Psychology, 22(2), 154-164. doi: 10.1207/s15374424jccp2202_3.

Connell, C., \& Prinz, R. (2002). The impact of childcare and parent-child interactions on school readiness and social skills development for low-income African American children. Journal of School Psychology, 40(2), 177-193. doi:10.1016/S0022-4405(02)00090-0.

Davis, H. L., \& Pratt, C. (1995). The development of theory of mind: The working memory explanation. Australian Journal of Psychology, 47, 25-31.

Denham, S. (2006). Social-emotional competence as support for school readiness: What is it and how do we assess it? Early Education and Development, 17(1), 57-89.

Denham, S., Blair, K., DeMulder, E., Levitas, J., Sawyer, K., Auerbach-Major, S., \& Queenan, P. (2003). Preschool emotional competence: Pathway to social competence. Child Development, 74(1), 238-256. doi: 10.1111/1467-8624.00533.

Diamantopoulou, S., Rydell, A.M., Thorell, L.B., \& Bohlin, G. (2007). Impact of executive functioning and symptoms of attention deficit hyperactivity disorder on children's peer relations and school performance. Developmental Neuropsychology, 32(1), 521-542.

Diamond, A. (2013). Executive functions. Annual Review of Psychology, 64, 135-168. doi:10.1146/annurev-psych-113011-143750.

Diamond, A., Barnett, W. S., Thomas, J., \& Munro, S. (2007). Preschool program improves cognitive control. Science, 318, 1387-1388. doi: 10.1126/science.1151148.

Dilworth-Bart, J. (2012). Does executive function mediate SES and home quality associations with academic readiness. Early Childhood Research Quarterly, 27, 416-425. doi: 
Running head: DOES SOCIAL-BEHAVIORAL ADJUSTMENT MEDIATE THE RELATION BETWEEN EXECUTIVE FUNCTION AND ACADEMIC READINESS?

10.1016/j.ecresq.2012.02.002.

Duncan, G. J., Dowsett, C. J., Claessens, A., Magnuson, K., Huston, A. C., ..., Japel, C. (2007). School readiness and later achievement. Developmental Psychology, 43(6), 1428-1446. doi:10. 1037/0012-1649.43.6.1428.supp.

Dunn, L. M., \& Dunn, L. M. (1981). Peabody Picture Vocabulary Test-Revised: Form M. Circle Pines, MN: American Guidance Service.

Durlak, J. A., Weissberg, R. P., Dymnicki, A. B.,Taylor, R. D., \& Schellinger, K. B. (2011). The impact of enhancing students' social and emotional learning: A meta-analysis of schoolbased universal interventions. Child Development, 82(1), 405-432. doi: 10.1111/j.14678624.2010.01564.x.

Eisenberg, N., Guthrie, I. K., Fabes, R. A., Shepard, S., Losoya, S., Murphy, B. C., et al. (2000). Prediction of elementary school children's externalizing problem behaviors from attention and behavioral regulation and negative emotionality. Child Development, 71(5), 13671382.

Espy, K. A., McDiarmid, M. M., Cwik, M. F., Stalets, M. M., Hamby, A., \& Senn, T. E. (2004). The contribution of executive functions to emergent mathematic skills in preschool children. Developmental Neuropsychology, 26(1), 465-486.

Fabrigar, L. R., Wegener, D. T., MacCallum, R. C., \& Strahan, E. J. (1999). Evaluating the use of exploratory factor analysis in psychological research. Psychological Methods, 3, 272-299. doi: 10.1037/1082-989X.4.3.272.

Fitzpatrick, C., McKinnon, D., Blair, C., \& Willoughby, M. (2014). Do preschool executive function skills explain the school readiness gap between advantaged and disadvantaged children? Learning and Instruction, 30, 25-31. doi: 10.1016/j.learninstruc.2013.11.003. 
Running head: DOES SOCIAL-BEHAVIORAL ADJUSTMENT MEDIATE THE RELATION BETWEEN EXECUTIVE FUNCTION AND ACADEMIC READINESS?

Friedman-Weieneth, J. L., Harvey, E. A., Youngwirth, S. D., Goldstein, L. H. (2007). The relation between 3-year-old children's skills and their hyperactivity, inattention, and aggression. Journal of Educational Psychology. 99, 671-681. doi: 10.1037/00220663.99.3.671.

Frye, D., Zelazo, P. D., \& Palfai, T. (1995). Theory of mind and rule-based reasoning. Cognitive Development, 10(4), 483-527. doi:10.1016/0885-2014(95)90024-1.

Fuhs, M. W., \& Day, J. D. (2011). Verbal ability and executive functioning in preschoolers at head start. Developmental Psychology, 47(2), 404-416. doi: 10.1037/a0021065.

Geoffroy, M., Côte, S., Giguère, C., Ginette, D., Zelazo, P.D., Trembaly, R., Boivin. M., \& Séguin, J. (2010). Closing the gap in academic readiness and achievement: The role of early childcare. Journal of Child Psychology and Psychiatry, 51(12), 1359-1367. doi: $10.1111 / \mathrm{j} .1469-7610.2010 .02316 . x$.

Gonçalves, M., Dias, P., \& Machado, B.C. (2007). Questionário de comportamentos da criança. Versão para educadores, cuidadores e auxiliares educativos: CTRF 1 1/2 - 5. Unpublished manuscript. University of Minho. Braga, Portugal.

Hamre, B., \& Pianta, R. (2001). Early teacher-child relationships and the trajectory of children's school outcomes through eighth grade. Child Development, 72(2), 625-638.

Hindman, A. H., Skibbe, L. E., Miller, A., \& Zimmerman, M. (2010). Ecological contexts and early learning: Contributions of child, family, and classroom factors during Head Start, to literacy and mathematics growth through first grade. Early Childhood Research Quarterly, 25(2), 235-250. doi:10.1016/j.ecresq.2009.11.003.

Jahromi, L. B., \& Stifter, C. A. (2008). Individual differences in preschoolers' self-regulation and theory of mind. The Merrill-Palmer Quarterly, 54, 125-150. 
Running head: DOES SOCIAL-BEHAVIORAL ADJUSTMENT MEDIATE THE RELATION BETWEEN EXECUTIVE FUNCTION AND ACADEMIC READINESS?

Kaiser, H. F. (1960). The application of electronic computers to factor analysis. Educational and Psychological Measurement, 20, 141-151. doi: 10.1177/001316446002000116.

La Paro, K. M. \& Pianta, R. C. (2000). Predicting children's competence in the early school years: A meta-analytic review. Review of Educational Research, 70(4), 443-484. doi: 10.3102/0034654307000443.

Ladd, G. W., \& Burgess, K. B. (2001). Do relational risks and protective factors moderate the linkages between childhood aggression and early psychological and school adjustment? Child Development, 72(5), 1579-1601.

Ladd, G. W., Birch, S. H., \& Buhs, E. S. (1999). Children's social and scholastic lives in kindergarten: Related spheres of influence? Child Development, 70(6), 1373-1400.

LaFreniere, P. J. \& Dumas, J. E. (1996). Social competence and behavior evaluation in children aged 3 to 6 years: The short form (SCBE-30). Psychological Assessment, 8(4), 369-377. doi: 10.1037/1040-3590.8.4.369.

Landry, S., Swank, P., Smith, K., Assel, M., \& Gunnewig, S. (2006). Enhancing early literacy skills for preschool children: Bringing a professional development model to scale. Journal of Learning Disabilities, 39(4), 306-324. doi: 10.1177/00222194060390040501.

Lonigan, C. (2006). Development, assessment, and promotion of preliteracy skills. Early Education and Development, 17(1), 91-114.

Lonigan, C. J., Bloomfield, B. G., Anthony, J., Bacon, K., Phillips, B., \& Samwel, C. (1999). Relations among emergent literacy skills, behavior problems, and social competence in preschool children from low- and middle-income backgrounds. Early Childhood Special Education, 19(1), 40-53. doi: 10.1177/027112149901900104.

Miedel, W., \& Reynolds, A. (1999). Parent involvement in early intervention for disadvantaged 
Running head: DOES SOCIAL-BEHAVIORAL ADJUSTMENT MEDIATE THE RELATION BETWEEN EXECUTIVE FUNCTION AND ACADEMIC READINESS?

children: Does it matter? Journal of School Psychology, 37(4), 379-402. doi: $10.1016 / \mathrm{S} 0022-4405(99) 00023-0$.

McWayne, C. M., Fantuzzo, J. W., \& McDermott, P. A. (2004). Preschool competency in context: An investigation of the unique contribution of child competencies to early academic success. Developmental Psychology, 40(4), 633-645. doi:10.1037/00121649.40.4.633.

Müller, U., Zelazo, P.D., \& Imsirek, S. (2005). Executive function and children's understanding of false belief: How specific is the relation? Cognitive Development, 20(2), 173-189. doi: 10.1016/j.cogdev.2004.12.004.

Nayfeld, I., Fuccillo, J., \& Greenfield, D. (2013). Executive functions in early learning: Extending the relationship between executive functions and school readiness to science. Learning and Individual Differences, 26, 81-88. doi: 10.1016/j.lindif.2013.04.011.

Nigg, J. T., Quamma, J. P., Greenberg, M. T., \& Kusche, C. A. (1999). A two-year longitudinal study of neuropsychological and cognitive performance in relation to behavioral problems and competencies in elementary school children. Journal of Abnormal Child Psychology, $27(1), 51-63$.

Oberle, E., \& Reichl, K. (2013). Relations among peer acceptance, inhibitory control, and math achievement in early adolescence. Journal of Applied Developmental Psychology, 34, 4551. doi: 10.1016/j.appdev.2012.09.003.

Palermo, F., Hanish, L., Martin, C. L., Fabes, R., \& Reiser, M. (2007). Preschoolers' academic readiness: What role does the teacher-child relationship play? Early Childhood Research Quarterly, 22(4), 407-422. doi: 10.1016/j.ecresq.2007.04.002.

Ponitz, C. C., McClelland, M. M., Matthews, J. S., \& Morrison, F. J. (2009). A structured 
Running head: DOES SOCIAL-BEHAVIORAL ADJUSTMENT MEDIATE THE RELATION BETWEEN EXECUTIVE FUNCTION AND ACADEMIC READINESS?

observation of behavioral regulation and its contributions to kindergarten outcomes. Developmental Psychology, 45, 605-619. doi: 10.1037/a0015365.

Preacher, K., \& Kelley, K. (2011). Effect size measures for mediation models: Quantitative strategies for communicating indirect effects. Psychological Methods, 16(2), 93-115. doi: $10.1037 / \mathrm{a} 0022658$.

Raver, C. C. (2002). Emotions matter: Making the case for the role of young children's emotional development for early school readiness. Social Policy Report, 16, 1-20. Washington: Society for Research in Child Development. Available at http://ideas.repec.org/p/har/wpaper/0206.html.

Raver, C., \& Knitzer, J. (2002). Ready to enter: What research tells policymakers about strategies to promote social and emotional school readiness among three- and four-year old children. New York, NY: National Center for Children in Poverty. Available at http://www.nccp.org/publications/pdf/text_485.pdf.

Riggs, N. R., Blair, C. B., \& Greenberg, M. T. (2003). Concurrent and 2-year longitudinal relations between executive function and the behavior of $1^{\text {st }}$ and $2^{\text {nd }}$ grade children. Child Neuropsychology, 9(4), 267-276.

Rimm-Kaufman, S., Pianta, R., \& Cox, M. (2000). Teachers' judgments of problems in the transition to kindergarten. Early Childhood Research Quarterly, 15, 147-166.

Romano, E., Babchishin, L., Pagani, L. S., \& Kohen, D. (2010). School readiness and later achievement: Replication and extension using a nationwide Canadian survey. Developmental Psychology, 46(5), 995-1007. doi: 10.1037/a0018880.

Roskam, I., Stievenart, M., Meunier, J., \& Noël, M. (2014). The development of children's inhibitory control: Does parenting matter? Journal of Experimental Child Psychology, 
Running head: DOES SOCIAL-BEHAVIORAL ADJUSTMENT MEDIATE THE RELATION BETWEEN EXECUTIVE FUNCTION AND ACADEMIC READINESS?

122, 166-182. doi: 10.1016/j.jecp.2014.01.003.

Röthlisberger, M., Neuenschwander, R., Cimeli, P., Michel, E., \& Roebers, C. (2011). Improving executive functions in 5- and 6-year-olds: Evaluation of a small group intervention in prekindergarten and kindergarten children. doi: 10.1002/icd.752. Infant and Child Development, 21(4), 411-429. doi: 10.1002/icd.752.

Rubin, K. H., Burgess, K. B., Dwyer, K. M., \& Hastings, P. D. (2003). Predicting preschoolers' externalizing behaviors from toddler temperament, conflict, and maternal negativity. Developmental Psychology, 39(1), 164-176. doi: 10.1037/0012-1649.39.1.164.

Sroufe, A. (1997). Emotional development: The organization of emotional life in the early years. Cambridge: Cambridge University Press.

Sroufe, A., Egeland, B., \& Kreutzer, T. (1990). The fate of early experience following developmental change: Longitudinal approaches to individual adaptation in childhood. Child Development, 61(5), 1363-1373. doi: 10.1111/j.1467-8624.1990.tb02867.x.

Starkey, P., Klein, A., \& Wakeley, A. (2004). Enhancing your children's mathematical knowledge through a pre-kindergarten mathematics intervention. Early Childhood Research Quarterly, 19(1), 99-129. doi: 10.1016/j.ecresq.2004.01.002.

Wanless, S., McClelland, M., Acock, A., Ponitz, C., Son, S. ... Li, S. (2011). Measuring behavioral regulation in four societies. Psychological Assessment, 23(2), 364-378. doi: $\underline{10.1037 / \mathrm{a} 0021768 .}$.

Wieber, S. A., Nelson, J. M., Clark, C. A., \& Espy, K. A. (2011). The structure of executive function in 3-year-olds. Journal of Experimental Child Psychology, 108(3), 436-452. doi: 10.1016/j.jecp.2010.08.008. 
Running head: DOES SOCIAL-BEHAVIORAL ADJUSTMENT MEDIATE THE RELATION BETWEEN EXECUTIVE FUNCTION AND ACADEMIC READINESS?

Valiente, C., Einsenberg, N., Haugen, R., Spinrad, T., Hofer, C., Liew, J., \& Kupfer, A. (2011). Children's effortful control and academic achievement: Mediation through social functioning. Early Education and Development, 22(3), 411-433. doi:10.1080/10409289.2010.505259.

Valiente, C., Lemery-Chalfant, K., Swanson, J., \& Reiser, M. (2008). Prediction of children's academic competence from their effortful control, relationships, and classroom participation. Journal of Educational Psychology, 100(1), 67-77. doi: 10.1037/00220663.100.1.67.

Zelazo, P. D., \& Carlson, S. M. (2012). Hot and cool executive function in childhood and adolescence: Development and plasticity. Child Development Perspectives, 6(4), 354360. doi:10.1111/j.1750-8606.2012.00246.x. 